\title{
PATRIMONIO CULTURAL INMATERIAL INDÍGENA: ANÁLISIS DE LAS POTENCIALIDADES TURÍSTICAS DE LOS SIMBOLISMOS DEL CACAO DEL PUEBLO BRIBRI (TALAMANCA, COSTA RICA)
}

\author{
David Arias-Hidalgo* \\ Instituto Tecnológico de Costa Rica \\ ESO- Espaces et Sociétés \\ https://orcid.org/0000-0002-3196-2881 \\ Maryland Morant González** \\ UniversitatPolitècnica de València \\ https://orcid.org/0000-0003-2339-9133
}

\section{RESUMEN}

El artículo explora las potencialidades de los simbolismos del cacao (Theobroma cacao), como elemento diferenciador del patrimonio cultural inmaterial, de la oferta turística indígena del pueblo bribri de Talamanca (Costa Rica), cuya estructura social se caracteriza por ser matrilineal. Se constata en base al análisis de los productos turísticos existentes, que la puesta en marcha de una estrategia de aprovechamiento del cultivo del cacao articulado en torno a sus simbolismos, en la oferta local de turismo, podría representar una oportunidad para diversificar los ingresos de las familias indígenas. Al mismo tiempo, serviría para dar a conocer unas señas de identidad únicas, desde la recuperación y conservación de las tradiciones, sin dejar de lado los riesgos que implica la patrimonialización del acervo cultural indígena.

Palabras clave: Turismo indígena; cacao; Abya Yala; sociedad matrilineal; patrimonio cultural inmaterial.

Fecha de recepción: 4 de mayo de 2020

Fecha de aceptación: 30 de septiembre de 2020

*Profesor en el Instituto Tecnológico de Costa Rica (Costa Rica) y doctorando en el laboratorio "Espaces et Sociétés - UMR 6590”. Universidad de Angers (Francia).E-mail: david.arias@itcr.ac.cr

**Universitat Politècnica de València (UPV)-Campus de Gandía. C/ Paranimf 1. 46730 Gandía VALENCIA (España).E-mail: maryland@upv.es 


\title{
Intangible indigenous cultural heritage: analysis of the tourist potential of the symbo- lism of cocoa for the bribri people (Talamanca, Costa Rica)
}

\begin{abstract}
The article explores the potential of the symbolism of cocoa (Theobroma cacao) as a unique element of the intangible cultural heritage that forms part the tourist offer of the indigenous Bribri people of Talamanca (Costa Rica). An analysis of the existing tourism products of the Bribri people - whose social structure is matrilineal - reveals that a strategy for using cocoa cultivation (based around its symbolism) in their tourism offer could help diversify the income of indigenous families. At the same time, without neglecting the risks of patrimonialising the indigenous cultural heritage, it would make known unique signs of identity by recovering and conserving traditions.
\end{abstract}

Keywords: indigenous tourism; cocoa; AbyaYala; matrilineal society; intangible cultural heritage.

\section{INTRODUCCIÓN}

En el momento actual, cuando el mundo se encuentra azotado por la pandemia causada por la Covid-19, la economía y, dentro de ella el sector turístico, se desploma, y nuestros modos de vida sufren grandes cambios, se hace, si cabe, más urgente escuchar seriamente las demandas, de los pueblos indígenas, que hasta el momento vienen sufriendo el embate de la globalización, y sobre todo de la colonialidad como estructura permanente del proceso civilizatorio de la modernidad (Quijano, 2000).

Como asegura Rodrigo Navarrete Saavedra en su artículo "Globalidad neoliberal y movimientos indígenas en América Latina”,

[...] lo que se denomina hoy globalización viene a representar una radicalización de una lógica profunda del sistema-mundo moderno, una nueva etapa del capitalismo tecnológicamente avanzado basado en las impresionantes transformaciones en las tecnologías de la comunicación y la información, y en el despliegue mundial del capital financiero que puede moverse a una velocidad sin precedentes, lo que altera la comprensión espacio-tiempo tradicional moderno y socava la capacidad del Estado-Nación para regular la política y lo social hacia adentro. Este proceso implica una serie de transformaciones socioculturales, pues modifica las dinámicas de identificación y nos pone en contacto de una nueva manera con una serie de "otros" en relación a los cuales redefinir la identidad y la diferencia. [...] Para el caso de América Latina lo más interesante de este proceso es la renovada visibilidad del movimiento indígena y un protagonismo político sin precedentes. (Navarrete, 2010: 4) 
La historia del turismo indígena va ligada necesariamente a las luchas de los pueblos por su liberación, tanto en la época colonial como en las posteriores etapas de conquistas económicas llevadas a cabo por el capitalismo mundial. A la larga historia de luchas y dominaciones que precede la vida y el posterior desarrollo del turismo en los pueblos indígenas, se ha de añadir, el proceso de turistificación en el que se han visto involucrados en los últimos años, en tanto que colectividades culturales tradicionales "ancestrales", algunas de ellas Patrimonio Cultural de la Humanidad, reconocido por la UNESCO, como parte de una "economía de la autenticidad" (Heinich, 2009; Oehmichen y De la Maza, 2019). A través de la puesta en marcha de iniciativas turísticas, algunas experiencias les ha permitido ser activos defensores de su cultura y territorio, creándose nuevas oportunidades de diversificación de sus rentas (Hale, 2002; Maldonado, 2006; Heinich, 2009; Cavaco, 2011; Menchen, 2012; Chaves, 2012; Jouault, 2018; Kieffer, 2018). El turismo indígena tiene una gran importancia a su vez, en relación a estrategias de cooperación internacional en busca de la reducción de la pobreza. Estas estrategias en el marco de metodologías como; Pro Poor Tourism (PPT) y Sustainable Tourism for Eliminating Poverty (ST-EP) han sido criticadas por su visión reduccionista de la pobreza, a la simple ausencia de ingresos de económicos en el contexto rural (Cañada, 2015; Milano, 2016).

El descubrimiento de la cultura como recurso para el desarrollo, es uno de los temas más recurrentes en el debate patrimonialista (Carrera y Dietz, 2005), abanderado por la Convención para la Salvaguardia del Patrimonio Cultural Inmaterial (UNESCO, 2003) y por la Convención sobre la Protección y Promoción de la Diversidad de las Expresiones Culturales (UNESCO, 2005). La cultura se ha convertido en la actualidad, en un pilar fundamental de la Declaración de Naciones Unidas sobre los Derechos de los Pueblos Indígenas (2007).

En este contexto en el que la cultura se constituye como recurso, se consolida la marca Sitio Patrimonio de la Humanidad, la Convención de Salvaguardia propicia el turismo en Sitios Patrimonio de la Humanidad, a partir del patrimonio inmaterial como dimensión social (Adie y Hall, 2017). Incluso en espacios no declarados, como Patrimonio de la Humanidad, pero que detentan características similares. Los nuevos destinos propician experiencias diferentes, centradas en la reinterpretación del patrimonio inmaterial (García, 2000; Aguilar, 2003).

Las universidades estatales de Costa Rica han ido atendiendo desde el año 2009, diferentes necesidades surgidas en las comunidades indígenas de Talamanca, a través de la realización de diversos proyectos en el territorio, a petición de las propias comunidades, dados los altos índices de pobreza y bajo desarrollo, con la finalidad de potenciar el turismo natural y cultural de forma sostenible. Los resultados que arrojan parte de los proyectos emprendidos por las universidades del país revelan, que las actividades turísticas llevadas a cabo todavía no han sido capaces de ordenar ni sistematizar la experiencia turística, sobre todo la relacionada con el patrimonio cultural inmaterial.

Partiendo de estas premisas, el presente trabajo se centra en el pueblo indígena bribri de Talamanca, Costa Rica, en el análisis de su estructura matrilineal, los simbolismos del cacao, su importancia en la producción agrícola y su potencial turístico desde el punto de vista del turismo indígena. 


\section{OBJETIVOS Y METODOLOGÍA}

El presente artículo, surge con base en dos investigaciones: el proyecto de tesis doctoral "La integración del turismo indígena y la dinámica agrícola: sus posibles impactos sobre los medios de subsistencia en Talamanca" financiado por el Ministerio de Ciencia, Tecnología y Telecomunicaciones de Costa Rica (MICITT) y el Instituto Francés de América Central (IFAC), y adscrito al Instituto Tecnológico de Costa Rica (ITCR) y al laboratorio Espaces et Sociétés (UMR 6590) (en el que se ha desarrollado gran parte del análisis del trabajo de campo y de revisión literaria del cacao, así como de la cosmovisión indígena y de género), Universidad de Angers, Francia; y el proyecto de investigación de la convocatoria ADSIDEO 2020 de la Universitat Politècnica de València (UPV) bajo el título: "Mejora del producto turístico de la comunidad indígena bribri (Talamanca, Costa Rica) mediante la puesta en valor de su Patrimonio Cultural Inmaterial" (a través del cual se están llevando a cabo propuestas de productos turísticos en base al Patrimonio Cultural Inmaterial indígena) cuyos investigadores pertenecen a la Universitat Politècnica de València (UPV) y al Instituto Tecnológico de Costa Rica (ITCR), en colaboración con la propia comunidad indígena bribri de Talamanca.

El objetivo principal del artículo ha sido, realizar un diagnóstico previo del Patrimonio Cultural Inmaterial (PCI) de la comunidad indígena bribri, centrado fundamentalmente en el modo de producción del cacao, con la finalidad última de proponer un producto turístico de mejora local y de empoderamiento de la comunidad, basado en su patrimonio inmaterial.

Para la consecución del objetivo principal, la investigación realiza metodológicamente, una revisión literaria sobre matriarcado y patriarcado en América, además de un repaso geo-histórico sobre la importancia del cacao en Costa Rica, para destacar aspectos de aquellas sociedades que hoy coinciden con lo que se ha dado en llamar: Patrimonio Cultural Inmaterial. Para el análisis de los simbolismos del cacao, los saberes tradicionales de sus cultivos y su relación con el turismo, se ha tomado como punto de referencia el trabajo etnográfico de David Arias Hidalgo en el periodo 2009-2014, durante la ejecución del programa de capacitación Guía Local Turístico Indígena (Arias y Solano, 2009) y el periodo 2018-2019 durante la realización del trabajo de campo en relación, a su investigación doctoral.

Las técnicas principales de investigación del trabajo de campo desarrollado se centraron, en la observación participativa y las entrevistas en profundidad, dirigidas a estudiantes de guiado turístico indígena, guías locales, representantes de los emprendimientos turísticos, kekepa (personas mayores) y awapa (médicos tradicionales). Para las entrevistas con algunos kekepa y awapa se contó con la colaboración de un intérprete de lengua bribri.

\section{MATRIARCADO, MATRILINIALIDAD Y PATRIARCADO EN EL CON- TEXTO DE ABYA YALA (AMÉRICA) Y COSTA RICA}

Los matriarcados y las sociedades matrilineales han sido objeto de estudio desde hace siglos. En el caso de los matriarcados, cabe resaltar algunas obras de referencia como es el caso de: El matriarcado: una investigación sobre la ginecocracia en el mundo antiguo según su naturaleza religiosa y jurídica de Johann Bachofen (1992) publicado por primera 
vez en 1861 y El enigma del matriarcado de Pablo Krische (1930). Siguiendo estas líneas, hay diversos autores que han realizado investigaciones no solamente sobre los matriarcados, sino también y asociado a ellos, a los sistemas matrilineales en las sociedades amerindias. En este sentido, citar el trabajo de Claude Lévi-Strauss en Las Estructuras elementales de parentesco (1969). En la actualidad ambos temas siguen siendo objeto de discusión para diversas disciplinas en las ciencias sociales.

Para Krische (1930), la existencia generalizada del matriarcado en los tiempos arcaicos de la humanidad muestra el predominio de un periodo de la historia, en el que en este tipo de sociedades, la mujer fue el eje central. Es decir, pueblos donde la mujer tuvo un rol dominante o de poder en la mayoría de los aspectos de la vida. Esto ha llevado a pensar que en las sociedades matrilineales actuales existen remanentes de ese matriarcado antiguo (Martín-Cano, 2005).

Las sociedades matrilineales no son lo mismo que los matriarcados. La característica principal en una sociedad matrilineal es la afiliación materna de la descendencia, en ese sentido, es un sistema de parentesco relativamente raro ya que los parientes del lado materno se reconocen con más fuerza que los parientes del lado paterno, en la definición de la organización social con una estructura compleja basada en reglas (Lévi-Strauus, 1969; Mattison, 2016). En la actualidad, por lo general, tanto en los sistemas de parentesco matrilineal como en el patrilineal, los hombres a menudo conservan posiciones de poder y autoridad dentro del grupo de parentesco (Lowes, 2020).

Para el caso de la región de Abya Yala, que hoy conocemos como América, encontramos posiciones antagónicas. Por un lado, se afirma desde los feminismos comunitarios, la existencia de un patriarcado autóctono que se combina con el patriarcado colonial (Cabnal, 2010; Paredes, 2013). En esa misma línea Rita Segato reafirma la idea de la existencia de un patriarcado histórico global:

El patriarcado es, así, no solamente la organización de los estatus relativos de los miembros del grupo familiar de todas las culturas y de todas las épocas documentadas, sino la propia organización del campo simbólico en esta larga prehistoria de la humanidad de la cual nuestro tiempo todavía forma parte. (Segato, 2003:15)

Por otro lado, Lugones (2008), señala que en América el género es una imposición colonial, esto lo hace basándose en el análisis de relaciones de género más equitativas que muestran grupos indígenas americanos principalmente en América del Norte. En ese sentido, cabe cuestionarse si existió un único patriarcado indígena como tal si la categoría de género no existía para estas sociedades.

Dos ejemplos de lo anterior los tenemos en Centroamérica. En primer lugar los indígenas kunas de Panamá pertenecientes a la familia chibcha, demuestran que género va mucho más allá del dimorfismo sexual. Entre los kunas existen los omegiid, son hombres que asumen una identidad afeminada, esta categoría en cierto grado desafía la noción de género a partir del binario masculino femenino (Martínez, 2014). Cabe destacar, que los kunas son matrilocales, su sistema de parentesco no es matrilineal, sino de descendencia bilineal; esto significa que la herencia se logra por parte del padre y de la madre (Morales, 1987). El otro ejemplo, que contrapone la noción de género universalista (hombre- 
mujer) lo encontramos en Mesoamérica, la investigadora indígena maya guatemalteca Aura Cumes, realiza un análisis la noción maya winaq del Popol Wuj (libro que recopila conocimientos mayas), según la autora la palabra significa persona o gente, y es contraria a la noción de "hombre" que es la medida de "lo humano" en occidente. Winaq no tiene género, hace referencia a la existencia de mujeres y hombres, de niñas y niños, de ancianas y ancianos (Cumes,2017).

En relación, al presente caso de estudio, los bribris son un grupo indígena que habita en Costa Rica y Panamá, su principal asentamiento se localiza en territorio costarricense, específicamente en la región de Talamanca. Los bribris pertenecen a la familia lingüística chibcha, son parte del área cultural intermedia o chínchense, en medio de dos áreas culturales importantes en América Latina: Área Mesoamericana y Área Andina (figura 1).

\section{Figura 1 \\ MAPA DE UBICACIÓN ÁREAS CULTURALES MESOAMERICANA, ANDINA Y CHIBCHENCE}

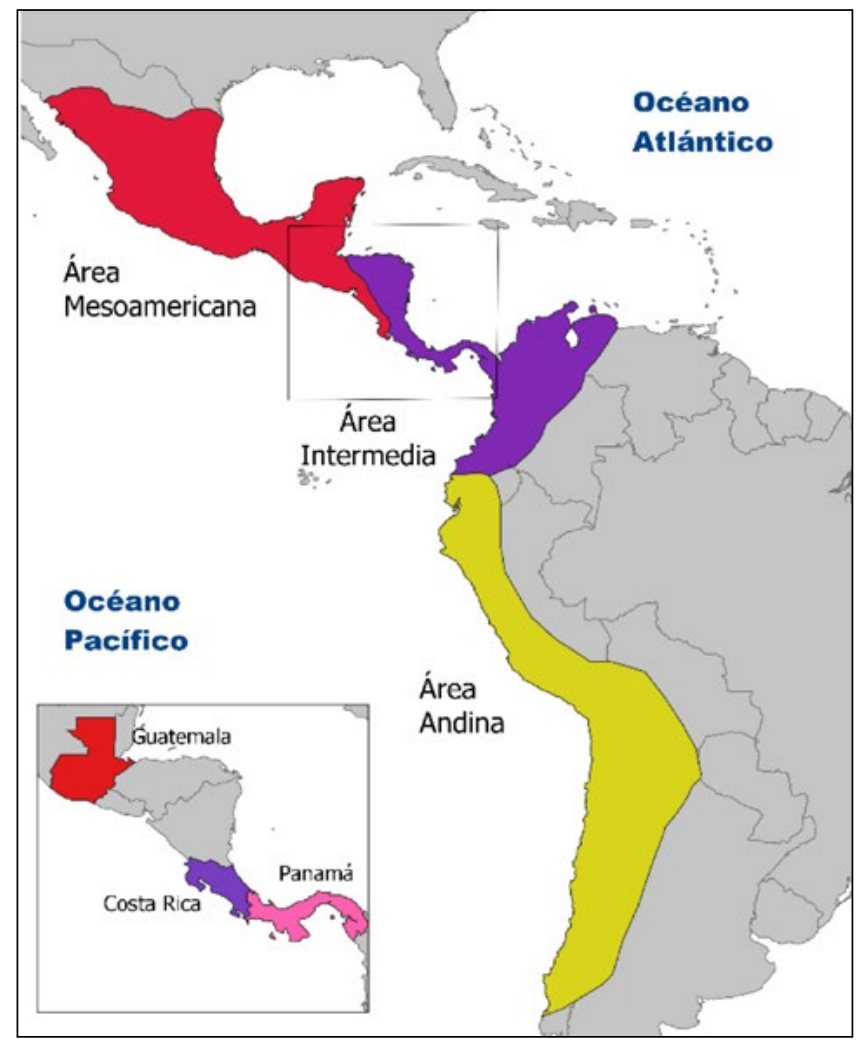

Fuente: Elaboración propia a partir de datos del proyecto de tesis doctoral "La integración del turismo indígena y la dinámica agrícola: sus posibles impactos sobre los medios de subsistencia en Talamanca." (2019). 
Los bribris junto a los cabécares, son los únicos pueblos indígenas costarricenses que poseen un sistema de parentesco matrilineal (Ruíz, Arias y Solano, 2019). En el caso de los bribris-cabécares, su estructura de afiliación matrilineal se caracteriza por su complejidad. Los bribris tienen un sistema de clanes matrilineales en mitades (Bozzoli, 1967). En la sociedad matrilineal bribri, la principal característica que persiste hoy es la herencia del clan por la vía materna, en este sentido, es la mujer quien determina quién es indígena bribri dentro de esta sociedad. Si el hombre bribri tiene descendencia con una mujer sin clan (no indígena) sus hijos no tendrán afinidad clánica.

En el pasado reciente, se ha documentado la existencia de relaciones más equitativas entre hombres y mujeres bribris. Bozzoli (1979) señala que las mujeres son las herederas de la tierra, pueden tomar bebidas alcohólicas y celebrar con libertad al igual que los hombres, inclusive pelear. En el pasado más lejano, se ha reportado el derecho al trono por clan materno y que la poligamia no estaba restringida a las mujeres, al igual que ejercer cargos de poder chamánico. Evidentemente, la sociedad bribri no es un matriarcado como tal, sin embargo, su cultura ancestral muestra diferencias importantes con un sistema patriarcal dominador.

En resumen, más allá del debate sobre cuál es el tipo de sociedad que predominó en Abya Yala (América), se reconoce una gran diversidad de realidades y contextos que sugieren que no existe un único sistema patriarcal y matrilineal que aplique para estas sociedades indígenas en general. En este estudio en particular sobre la sociedad bribri, son de interés los elementos culturales que desafían la lógica de un sistema de dominación patriarcal occidental. Sin negar la gran influencia del proceso de transculturación y las transformaciones profundas de la colonialidad de género, es decir, tomar en cuenta más de 500 años de la imposición de un sistema moderno colonial de género (Lugones, 2008).

También cabe preguntarse, si en el presente existen remanentes de una sociedad más equitativa en cuanto a la relaciones de género a lo interno de las organizaciones de turismo dentro del Territorio Indígena Bribri, y cómo esto se vincula con el turismo, su sistema de parentesco matrilineal, la tradición oral y la cosmovisión, en el sentido de poner en valor el patrimonio cultural inmaterial dentro de la oferta turística local.

\section{PATRIMONIO CULTURAL INMATERIAL Y PUEBLOS INDÍGENAS}

Todos los pueblos del mundo han construido y forjado alguna expresión que consideran lo que hoy se denomina patrimonio cultural inmaterial. En el año 2006, con la ratificación de los acuerdos tomados en la Convención para la Salvaguardia del Patrimonio Cultural Inmaterial (UNESCO, 2003), se consiguió un avance planetario al legitimar desde la oficialidad internacional la relevancia de los bienes patrimoniales intangibles como "crisol de la diversidad cultural y garante del desarrollo sostenible" (Chang, 2017). En el texto de la Convención se define patrimonio inmaterial como:

los usos, las representaciones, las expresiones, los conocimientos, las habilidades, así como los instrumentos, objetos, artefactos y espacios culturales asociados a 
ellos, que las comunidades, los grupos y, en algunos casos, los individuos reconocen como parte integrante de su patrimonio cultural. (art.2.1)

En el documento, se hace referencia a la forma de transmitir el patrimonio de generación en generación, y en este sentido, en la condición dinámica del mismo, ya que se construye a través de la expresión de identidad de las propias comunidades. Algunos promotores del texto de la Convención, aspiraban a conseguir con la redacción del proyecto, entre otros requerimientos, el respeto de los derechos de las comunidades, grupos e individuos sobre su propio patrimonio, así como la apuesta por la sostenibilidad (Munjeri, 2009). En la definición de Patrimonio Cultural Inmaterial de la Convención, la salvaguarda es el punto desde el que se proyectan todas las perspectivas y posiciones hasta llegar a la utilidad del patrimonio local (Jiménez, 2020).

Con la Convención para la Salvaguardia del Patrimonio Cultural Inmaterial, se ha dado paso a un mayor reconocimiento de la relación existente entre las comunidades y su patrimonio (Naciones Unidas, 2015).

Como complemento a la Convención para la Salvaguardia, en el año 2005 se adopta la Convención sobre la Protección y Promoción de la Diversidad de las Expresiones Culturales (UNESCO, 2005), encaminada a la salvaguarda de la diversidad cultural frente a la homogeneización que orienta la mundialización y que señala que:

la diversidad cultural se manifiesta no sólo en las diversas formas en que se expresa, enriquece y transmite el patrimonio cultural de la humanidad mediante la variedad de expresiones culturales, sino a través de distintos modos de creación artística, producción, difusión, distribución, disfrute de las expresiones culturales, cualesquiera que sean los medios y tecnologías utilizadas. (art.1)

Desde diversos organismos internacionales se ha trabajado durante las últimas décadas, en iniciativas y propuestas de protección del patrimonio cultural de grupos minoritarios, aunque en la actualidad todavía no existe una integración de todos los elementos que garanticen la protección total de los pueblos indígenas y su cultura. Los diferentes marcos jurídicos y declaraciones existentes se olvidan, en la mayoría de los casos, de las conexiones que hay entre el patrimonio inmaterial, las tierras y los territorios.

Pese a la dispersión normativa y documental, se puede afirmar que están habiendo avances en los "modelos de desarrollo" de las manifestaciones culturales de colectivos minoritarios excluidos tradicionalmente, como es el caso de las comunidades indígenas. Se pretende avanzar en los llamados "nuevos patrimonios", en los que se incluyen actividades de diferentes grupos sociales vinculados a territorios, objetos y prácticas que reposan más en una cuestión de representatividad y reivindicación de los colectivos (Quintero, 2005). También debe de tenerse en cuenta que, dentro de estos nuevos modelos de desarrollo, el patrimonio cultural inmaterial relacionado con las comunidades indígenas está asociado a una construcción social dinámica, que se va renovando según las transformaciones que sobre el mismo se va sucediendo, por lo que dicho patrimonio no solamente es digno de ser conservado, sino también transmitido de generación en generación (Prats, 2007; Endere, 2009; Giacomasso, 2017). 


\subsection{Turismo indígena}

El concepto de turismo indígena es impreciso y además ambiguo. Se le ha relacionado con diversas tipologías turísticas como son el turismo rural, el turismo comunitario, el ecoturismo, el turismo alternativo, el agroturismo y el turismo étnico. Todas estas modalidades tienen rasgos comunes de integración con las poblaciones locales, respeto por la cultura y la sostenibilidad, sin embargo, el turismo indígena implica explícitamente la presencia de comunidades indígenas porque la cultura es la esencia del atractivo, a diferencia por ejemplo del turismo étnico, que no contempla necesariamente grupos indígenas. Pero sobre todo se relaciona con un "modo de hacer" turismo, en el que los indígenas son los agentes centrales del empoderamiento (Grünewald, 2003; Yang y Wall, 2009; Pereiro, 2015); esta forma de hacer turismo tiene una gran importancia en relación a las estrategias internacionales de la reducción de la pobreza tal y como se señala en los Objetivos de Desarrollo Sostenible (ODS) 2030 (ONU, 2015).Como se comentaba en el apartado anterior, el Patrimonio Cultural Inmaterial se usa socialmente cada día en mayor medida, convirtiéndose en un producto turístico cada vez más demandado y como oportunidad de desarrollo de los territorios, sobre todo para pequeñas comunidades. El incremento del interés por las tradiciones, costumbres y expresiones culturales indígenas, por parte de la industria del turismo, ha transformado al patrimonio cultural inmaterial en fuente de identidad y creatividad práctica de la sociedad que lo conforma (Delgado, 2008; Hernando, 2009; López y Marín, 2010; Marcos, 2010; Olivera, 2011; Boude y Luna, 2013; Flores y Nava, 2016).

A pesar de las declaraciones y documentos para la mejora a nivel internacional del movimiento indígena y del turismo ${ }^{1}$ (con instrumentos que presentan propuestas de modelos de autogestión comunitaria indígena, así como medidas legales para favorecer el turismo), en general puede decirse que, en la actualidad, las comunidades indígenas siguen excluidas de los beneficios y del control cultural del desarrollo turístico (Coronado, 2014; Valcuende, 2017). La gestión de emprendimientos turísticos por parte de las comunidades indígenas se ve limitada por la falta de experiencia profesional en el sector, la falta de formación, así como por los repartos desiguales de beneficios del turismo entre tour operadores y las propias comunidades (Fuller et al., 2005 y 2007; Bennett et al., 2012; Witford y Ruhanen, 2014; Pastor y Espeso, 2015).

Autores como Pereiro (2015), hacen referencia a que nos encontramos ante un campo científico abierto en relación al turismo indígena, resaltando que se han llevado a cabo estudios desde los años 90 hasta la actualidad, resumiendo la perspectiva del autor, que se trata más de una oferta de producto, que una forma de hacer turismo.

Lo que se puede afirmar a partir de los datos del presente documento, es que, en los últimos años, se ha producido un giro en la concepción del Patrimonio Cultural Inmaterial,

1 Entre los documentos, declaraciones y cumbres internacionales relacionadas con la mejora del movimiento indígena y el turismo cabe destacar: Declaración por la ONU del Año Internacional de los Pueblos Indígenas (1993); Declaración de Otovalo sobre Turismo Comunitario Sostenible, Competitivo y con Identidad Cultural (2001); Cumbre Mundial de Johannesburgo (2002); la Cumbre Mundial del Ecoturismo de Quebec (2002); Foro Internacional del Turismo Indígena en Oaxaca (2002); Declaración sobre Turismo Rural Comunitario (2003); Declaración de Naciones Unidas sobre Derechos de los Pueblos Indígenas (2007). 
arrojando como resultado trabajos y estudios relacionados con nuevas tipologías turísticas sostenibles llevadas a cabo, a través de iniciativas lideradas en comunidades indígenas, sobre todo de América Latina, basadas en el enfoque del "Desarrollo Rural Territorial con Identidad Cultural” (DRT-IC) (Pérez, 2008). Lo que parece más que evidente, es que la cultura se está convirtiendo en un pilar básico de desarrollo, en el que las experiencias acumuladas hasta el momento han tratado de precisar una forma de turismo en la que más que producto para vender, se convierte en un modelo real de desarrollo, que sirve para diversificar las labores productivas existentes.

En cuanto a la patrimonialización del acervo cultural, nos encontramos con posiciones contrapuestas. Por un lado, Aicken y Ryan (2005) señalan que el turismo en comunidades indígenas ofrece oportunidades para el renacimiento cultural, la generación de ingresos y un mayor empoderamiento político, pero también hay posibles costos de crear bienes a partir de aspectos de la vida común. Por otro lado tenemos las críticas de Johnston (2006) en su obra Is the Sacred for Sale? Tourism and Indigenous Peoples, quien señala que en algunas ocasiones el turismo indígena se presta para prácticas contraproducentes para los derechos indígenas, la conversión en mercancías de los individuos y comunidades indígenas, y por ende, la pérdida de cultura e identidad. En la misma línea, tenemos las críticas sobre la comercialización de la cultura indígena en la lógica de humanizar el ajuste neoliberal en América Latina en la década de los años 90 y 2000, en este sentido, desde Bolivia Silvia Rivera Cusicanqui sostiene:

... a la tecnocracia sobre la necesidad de "humanizar el ajuste". El corolario fue un multiculturalismo ornamental y simbólico, con fórmulas como el "etno-turismo" y el "eco-turismo", que ponían en juego la teatralización de la condición "originaria", anclada en el pasado e incapaz de conducir su propio destino.(Rivera, 2010:58)

La turistificación de los pueblos indígenas muestra la manera en que el multiculturalismo neoliberal incorpora a los pueblos indígenas bajo ciertas condiciones, al mismo tiempo que los excluye bajo otras, a partir del análisis de las experiencias de pueblos indígenas y su patrimonio cultural en México y Chile, en este sentido Cristina Oehmichen y Francisca de la Maza afirman que:

El proceso de turistificación y la participación de las comunidades, no escapa del enfoque del mercado que busca integrar la diferencia cultural a través de la folclorización de las expresiones culturales indígenas, algunas de las cuales son reconocidas por la UNESCO como "patrimonio cultural intangible" de la humanidad. (Oehmichen y De la Maza, 2019:61)

El proceso de institucionalización de la cultura y su patrimonialización, acompañada de un despliegue legitimador, es un interesante campo de estudio (Asencio y Pérez,2012), de tal forma, que abrir al turismo una actividad cultural en el contexto de una comunidad indígena implica riesgos y al mismo tiempo oportunidades. De ahí la importancia de su participación en la planificación de dicha actividad y en la toma de decisiones, en el sentido de preguntarse, qué aspecto cultural puede abrirse al turismo, qué reglas o códigos 
de conducta se deben tomar en consideración dentro una oferta turística controlada por la comunidad receptora, en el marco de la construcción de un imaginario turístico.

\section{TURISMO EN LAS COMUNIDADES INDÍGENAS BRIBRIS}

La población indígena de Costa Rica está distribuida en 24 territorios indígenas, y ocho etnias, entre ellas: malekus, nogbes, brunkas, térrabas, huetares, chorotegas, bribris y cabécares (Guevara, 2000). La mayoría de la población indígena bribri se concentra en los cantones de Talamanca en la provincia de Limón y Buenos Aires, provincia de Puntarenas. En la actualidad se mantienen con mayor grado de conservación los idiomas indígenas: bribri, cabécar, malekjaica y las lenguas nogble-buglé.

En general, los pueblos indígenas están ubicados entre los distritos más marginales del país con índices de desarrollo humano muy bajos. Un ejemplo es Talamanca (caso de estudio que se ocupa), con el $60 \%$ de la población indígena de Costa Rica. Talamanca es el cantón más pobre: registra la posición 81 tanto en el Índice de Desarrollo Humano (IDH) como en el Índice de Rezago Social (IRS) en el año 2000, mientras que el cantón central de San José ocupa el lugar 9 en el Índice de Desarrollo Humano y el lugar 16 en el Índice de Rezago Social (MIDEPLAN, 2013; Vargas, 2016).

A pesar de las mejoras en políticas sociales y económicas que han experimentado algunos pueblos indígenas en la última década (Banco Mundial, 2015), a día de hoy siguen viviendo una fuerte exclusión que les limita, sin tener que renunciar a su cultura e identidad, la capacidad de contribuir al Estado y de beneficiarse de sus servicios. Si tomamos algunos datos del estudio realizado por el Banco Mundial, podemos mencionar que solo entre el $61 \%$ y el $68 \%$ de los residentes indígenas tiene acceso al agua en sus hogares; según el último censo actualizado (INEC, 2011), el 80\% de los hogares indígenas tenía electricidad frente al $99 \%$ de los hogares no indígenas. Si hablamos de educación, vemos que el analfabetismo es del 7,7\% entre los indígenas y del 2,2\% entre los no indígenas, lo que se traduce en menores oportunidades de empleo.

Aunque se puede decir que el acceso a los servicios sí ha mejorado considerablemente, estos no están adaptados a su cultura, por lo que los grupos a los que van dirigidos no obtienen el máximo provecho de ellos. El Territorio Indígena Bribri de Talamanca (figura 2) se ubica en la cuenca del río Sixaola, cantón de Talamanca, provincia de Limón (Costa Rica). Su extensión es de 43.690 hectáreas, e incluye los distritos de Telire y Bratsi, que están parcialmente dentro del Valle de Talamanca, en las subcuencas Telire, Yorkín, Urén y Lari. La población bribri de Talamanca es de 8.368 habitantes (según los últimos datos de censo conseguidos hasta la actualidad). La principal actividad económica en el cantón es la agricultura basada en el cultivo de banano y cacao. A esta actividad se ha sumado un incipiente desarrollo del turismo como actividad complementaria (Arias y Solano, 2009; Arias-Hidalgo, 2016). El idioma que se habla es el bribri, con dos variedades dialectales en Talamanca, pero una mayoría en las nuevas generaciones no dominan el idioma en su totalidad, en favor del castellano. 


\section{Figura 2 \\ MAPA DE UBICACIÓN DEL TERRITORIO INDÍGENA BRIBRI DE TALAMANCA, COSTA RICA}

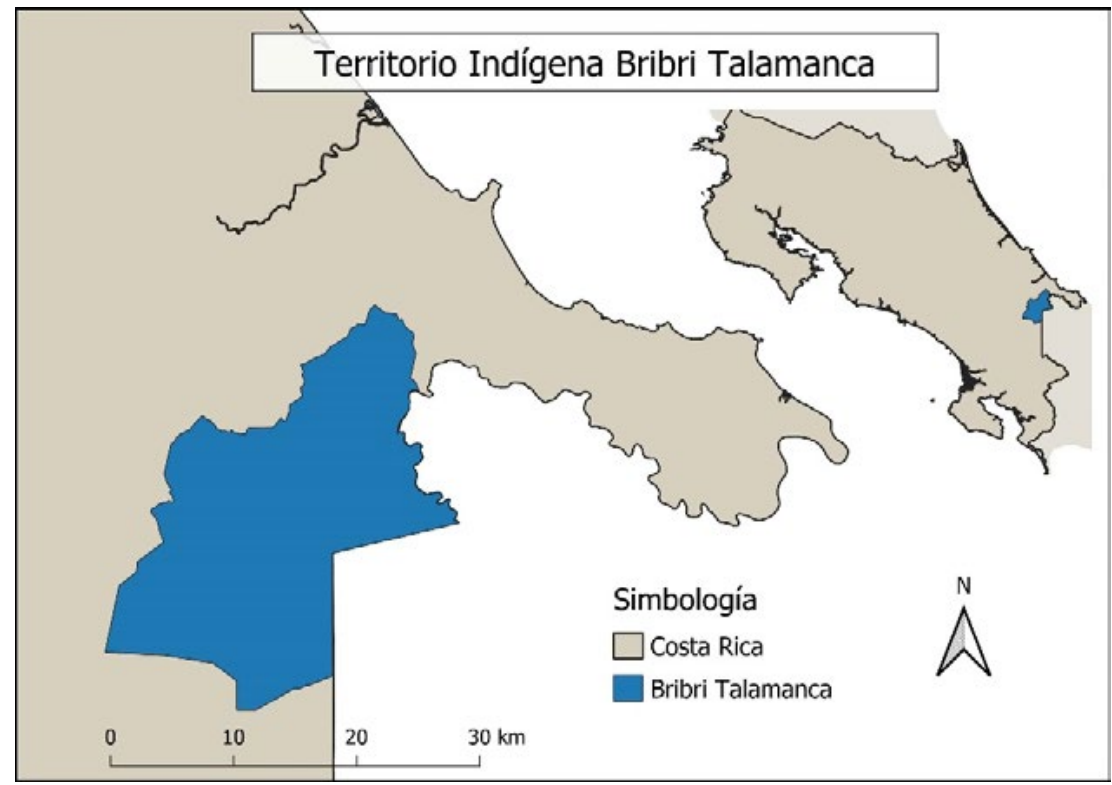

Fuente: Arias (2019).

El pueblo bribri en general, es uno los que más ha trabajado en relación a las actividades turísticas, siendo los Territorios Indígenas de Talamanca Bribri, Kekoldi y Salitre, los quehan desarrollado una mayor planta turística de hospedaje, tipo cabañas y albergues rústicos, que rescatan la arquitectura tradicional (Arias-Hidalgo y Méndez-Estrada, 2015). Otras actividades turísticas que realizan los bribris en Talamanca son: los tours de elaboración cacao, avistamiento de aves migratorias, venta de artesanías y visitas a fincas orgánicas. Actualmente existen tres empresas bribris con declaratoria turística, lo cual muestra un avance en el grado de formalización de los emprendimientos turísticos indígenas. Dos de ellas, se ubican en el territorio indígena de Talamanca: la Asociación de Guías locales Indígenas Bribris de Talamanca (AGITUBRIT) la Finca Agro-turística Siwakabata, en el Territorio de Salitre la Asociación Bribripa. Estas empresas con declaratoria turística lideradas por indígenas, muestran un avance en grado de formalización de los emprendimientos turísticos indígenas ante el Instituto Costarricense de Turismo (ICT).

En Talamanca existen alrededor de 7 albergues turísticos, las principales comunidades del Territorio Indígena Bribri que reciben turismo de forma más constante son: Yorkin, Amubri, Bambú, Suretka y Shiroles (Arias-Hidalgo y Méndez-Estrada; 2015; Arias-Hidalgo; 2016), y en los últimos años, la comunidad de Shuabb en la cuenca del río Yorkín con el albergue turístico ACETA (Asociación de Agricultura Orgánica y Eco- 
turismo de Telire Talamanca) liderada por mujeres de dicha comunidad (Arias-Hidalgo, Aguilar-Álvarez y Reinhold, 2019).

Los emprendimientos de turismo en las comunidades indígenas bribris de Talamanca se caracterizan por su pequeña escala, concentrándose en la actualidad el mayor número de visitas en la comunidad de Yorkín. En general, la principal característica de los proyectos turísticos de hospedaje y recorridos turísticos (tours) es el alto grado de control local en la gestión de su actividad turista.

\section{ELPOTENCIAL DE LA PRODUCCIÓN Y SIMBOLISMOS DEL CACAO PARA EL MEJORAMIENTO DEL PCI DE LAS COMUNIDADES BRIBRIS}

\subsection{Breve reseña geo-histórica del cultivo del cacao y su importancia a nivel regional, nacional y local}

El cacao (Theobroma cacao) es una planta tropical nativa del continente americano, probablemente este cultivo tropical tenga sus inicios en la cuenca de la Amazonia (Alvim, 1977). El cultivo ha sido trascendente en América Central desde tiempos prehispánicos, los Mayas lo domesticaron hace unos 1500 años y aunque existe un debate sobre los orígenes de esta planta, los estudios en diversidad genética evidencian sus orígenes en América del Sur y posiblemente diseminado por el ser humano en Centroamérica (Motamayor et al., 2002). Por ejemplo, se reporta para la Región Maya una considerable evidencia que demuestra que el cacao estuvo presente durante el periodo Clásico (250-900 d.C.) y el Posclásico (900-1500 d.C.), muy probablemente las bebidas elaboradas con cacao eran fermentadas o alcohólicas (Powis et al., 2008).

En el periodo pre-hispánico, para los indígenas de Costa Rica fue un cultivo de gran importancia para su economía, se sabe, según algunas investigaciones, usos variados como por ejemplo: bebida espiritual, medio de intercambio, medicina y tributo (Fonseca, 1983). Registros para fechas tempranas de la colonización, indican que existían plantaciones de cacao entre los indígenas de Talamanca y los Votos al norte del país (MacLeod, 1996).

La producción de cacao tiene una larga historia en Costa Rica, en el siglo XVII después de la colonización española, el ciclo comercial del cacao se extiende de los años 1650 a 1800 (MacLeod, 1996). El cultivo fue impulsado por migrantes y gobernadores de Costa Rica que tenían sus plantaciones principalmente en el Caribe costarricense, específicamente en Matina (Fonseca, 1983).

Según MacLeod (1996), el auge de la producción cacaotera coincidió con la ocupación británica de Jamaica en 1655. Los mercaderes británicos pudieron haber incentivado a los costarricenses para que cultivaran los árboles de cacao silvestre que crecían en la región.

Un aspecto sobresaliente, es que el cacao fue utilizado como moneda durante el periodo colonial, como medio de pago de los bienes y servicios, esto refleja la importancia del cultivo en ese periodo, además de una difícil situación económica en Costa Rica y la ausencia de moneda de plata necesaria para las transacciones de bienes y servicios internos (Chacón, 2014). 
El cultivo tuvo un estancamiento en 1690 y declive a finales del siglo XVIII (MacLeod, 1996). Acuña (2002), sugiere que el cultivo de tabaco adquirió mayor importancia después de 1760 , lo cual coincide con el inicio de la decadencia del cacao.

Las causas del declive del cacao son varias, entre ellas: el clima difícil, la falta de mano de obra, la carencia de mercados, los caminos intransitables y la invasión de piratas ingleses y miskitos (Fonseca, 1983). Los miskitos eran indígenas del Caribe nicaragüense y hondureño, quienes incursionaron en siglo XVIII en varias ocasiones a Talamanca, con el fin de capturar y vender a los indígenas como esclavos (Ibarra, 2010; Solórzano, 2017). También en ese mismo periodo se puede asociar la esclavitud afro con el cultivo de cacao, específicamente inmigrantes forzados (afrodescendientes) que reemplazaron a los indígenas urinamas (indígenas de Talamanca) como mano de obra principal en el cultivo de los cacaotales (Cáceres, 2000).

Se sabe que el cacao siguió siendo un cultivo importante en la zona fronteriza de Sixaola, se reportaba que la United Fruit Company desde 1932 hasta 1941, tuvo un promedio anual de poco más de 4 millones de kilos de cacao seco producidos al año en unas 9.600 hectáreas (Bourgois, 1994). Esto después de su salida del Territorio Indígena Bribri y cultivando en tierras afectadas por la enfermedad de Panamá, que afectó las plantaciones de banano.

Según Hidalgo-Capitán (2003), a finales del siglo XX, la producción de cacao se redujo hasta niveles marginales, a pesar de los esfuerzos realizados a mediados de los ochenta por establecer plantaciones comerciales; la aparición de problemas de carácter biotecnológico, junto con la caída de los precios, han propiciado el abandono o la sustitución de los cacaotales por cultivos más rentables.

Esta tendencia al decrecimiento continuó en el siglo XXI, además, los tres últimos censos agropecuarios al año 2014, muestran un comportamiento a la baja en el total de fincas (Carmiol, 2017).

A nivel del cantón de Talamanca, el cacao sigue siendo un producto agrícola importante. A modo de ejemplo, cabe mencionar a la Asociación de Pequeños Productores de Talamanca (APPTA), en donde se recoge gran parte de la producción de cacao orgánico proveniente de las comunidades indígenas bribris y cabécares. Este cacao es secado en APPTA y exportado al mercado europeo. La producción de cacao proveniente del territorio indígena por lo general tiene poco valor agregado y se vende a intermediarios para su procesamiento. Este proceso, arroja beneficios económicos limitados para las familias indígenas. Cabe resaltar un estudio sobre comercialización del cacao llevado a cabo en Yorkín, comunidad bribri reconocida por su constante demanda turística, para una mejor comprensión del proceso:

Existen dos empresas reconocidas que compran cacao APPTA y Koproxa. La comunidad de Yorkín vende una porción de su cosecha a Koproxa, una comercializadora de cacao de propietarios de nacionalidad española, que posee un centro de acopio en la comunidad de Suretka circunvecina a Yorkín, en donde compran, acopian, fermentan y secan cacao húmedo; luego trasladan el cacao seco hasta una planta industrial de su propiedad, situada en el Puerto de Colón, Panamá, en donde la procesan y transforman en productos intermedios como el licor, la manteca y el polvo de cacao, así como en chocolate de variadas presentaciones. (Chaves, Salazar y Robles, 2016: 6-7) 


\subsection{El cacao y su relación con el turismo en Talamanca}

Como mencionábamos anteriormente, el Caribe costarricense ha sido una región histórica en la producción del cacao. A finales de la década de los años 70, el hongo de la monilia (enfermedad que daña los frutos del cacao) tuvo una seria afección en las plantaciones del Caribe Sur y Talamanca, llegando casi a la totalidad de pérdida de la producción del cacao de la región.

Para las familias indígenas en la comunidad de Yorkín, el cacao representaba una fuente de ingresos económicos importante. Por ello, con la disminución de la producción se debilitó la economía de muchas familias, un fenómeno que prácticamente afectó a toda Talamanca. La situación económica difícil provocada por la monilia supuso, una de las principales motivaciones para que las mujeres de Yorkín, buscaran otras alternativas económicas complementarias a la producción de cacao en la comunidad. La alternativa más sólida que emprendieron se centró, en la puesta en marcha de actividades turísticas, aprovechando los recursos naturales singulares de la zona, sobre todo los relacionados con el río Yorkín y el bosque de su comunidad, además de aprovechar a su vez, la oportunidad de atraer turistas desde los dos destinos cercanos de playa del Caribe costarricense (Puerto viejo y Cahuita). Tras algunos años de puesta en valor turística de su patrimonio, este grupo de mujeres, consolidarían el primer emprendimiento de turismo de Talamanca, a finales de los 80 y principios de los 90, bajo el nombre de: Asociación Stibrawpa, que significa en bribri personas artesanas, un nombre muy ligado a la actividad inicial de la organización: la venta de artesanías.

En la actualidad, tanto la asociación, como sus actividades, constituyen uno de los proyectos de turismo comunitario indígena más reconocidos de Costa Rica. Stibrawpa, cuenta con alrededor de 45 socios (mujeres y hombres) de la comunidad de Yorkín principalmente, así como de otras comunidades vecinas. Su junta directiva está compuesta sólo por mujeres, son ellas las que toman decisiones además de que siempre van a detentar el control de Stibrawpa. Este emprendimiento es considerado como un ejemplo de transformación positiva en empoderamiento en las relaciones de género y turismo en el contexto de comunidades rurales (Cañada, 2019). Por supuesto, la preparación del chocolate es parte de la oferta turística de este emprendimiento liderado por mujeres. También cabe resaltar, que en Yorkín se localiza otra iniciativa turística: Aventuras Naturales Yorkín, quienes instalaron una pequeña planta procesadora de cacao en 2014.

Hoy la mayoría (alrededor del 90\%) de los emprendimientos turísticos del Territorio Indígena Bribri de Talamanca, ponen en valor dentro de su oferta turística, algún elemento relacionado con el cacao, destacando los tours a las plantaciones y la demostración del proceso de elaboración de la pasta de cacao que los bribris llaman tsiruska (pasta de chocolate).

Otro buen ejemplo de emprendimiento femenino y producción de cacao con valor añadido, es la Asociación de Mujeres Indígenas de Talamanca (ACOMUITA), ubicadas en la comunidad de Shiroles. La asociación de mujeres ACOMUITA procesa, vende chocolates y ocasionalmente reciben turistas. En Suretka, existen tours de cacao (doña Erminia), y en la comunidad de Meleruk el proyecto familiar Casa Aiko, donde se reciben turistas, además de procesar y vender cacao en polvo y en pasta. 
Tal y como se ha visto a través de los diferentes ejemplos citados, queda reflejado el aprovechamiento del cultivo y el proceso del cacao dentro de la oferta turística, así como la participación activa de grupos organizados de mujeres. Por otro lado, los resultados obtenidos a través del trabajo de campo realizado con emprendimientos turísticos (liderados por mujeres), y guías locales indígenas, además de diversas conversaciones y entrevistas en profundidad mantenidas con personas mayores (kekepa) y médicos tradicionales (awapa), ambos conocedores del siwã, nos sugieren que actualmente existe un considerable acervo cultural, relacionado con los simbolismos del cacao. Los resultados de los estudios obtenidos en los diferentes emprendimientos turísticos evidencian que, su puesta en valor es mínima, centrándose la parte fundamental de la oferta turística actual, en el procesamiento del cacao para la elaboración de chocolate (pasta y bebida) y en ocasiones la visita a las plantaciones. Cabe aquí preguntarse, a qué se debe la ausencia de una interpretación del patrimonio inmaterial, cuyo discurso se centre en los simbolismos del cacao, sus tradiciones y costumbres. Probablemente, a manera de hipótesis, esto tenga que ver con la pérdida de estos conocimientos por parte de la mayoría de la población o la necesidad de una mejora de las técnicas interpretativas empleadas para la puesta en valor de las tradiciones y costumbres que giran en torno al cacao por parte de los guías turísticos indígenas.

A modo de conclusión, podemos decir a la vista de los resultados obtenidos en el trabajo de campo y la revisión bibliográfica, que el cacao es un recurso, que tanto hombres como mujeres bribris, aprovechan en su oferta turística, siendo las mujeres quienes lideran los proyectos para su puesta en valor turística. Esto podría estar relacionado con el simbolismo femenino que representa el cacao dentro de la cosmovisión bribri y con su estructura histórica matrilineal.

\subsection{Los simbolismos del cacao y su potencial para la puesta en valor turística como PCI de los bribris}

Cacao, tsirú en la legua bribri, se asocia con los intercambios, la hospitalidad y las relaciones de reciprocidad (Bozzoli,1980), también representa la feminidad entre los bribris y cabécares, es uno de los elementos más simbólicos en su cultura, y está bien representado en su rica tradición oral. Es decir, su siwã, el mejor ejemplo es la historia del origen del cacao (la mujer cacao), aquí una versión:

Los mayores la cuentan y a nosotros pequeños se nos graba eso en la cabeza. Estas eran cuatro: SkwaLöm, Tsiru', SLo' y Wëröm. En ese tiempo venían hombres elegantes, estas mujeres les gustaban a estos hombres, y tenían a Cacao como despreciable porque era fea. Estos hombres se dedicaban a la cacería de pájaros, pero con cerbatana, y estos hombres mataban los mejores pájaros, por eso estas mujeres querían a estos hombres y nadie quería a Cacao. En eso Sibö se apareció a Cacao. Sibö se hizo en la misma imagen de Cacao, despreciado. Sibö mataba las malas clases de pájaros. Sibö llevaba estos pájaros a Cacao para que los preparara. Las otras tres preparaban lo que esos hombres cazaban, y cenaban; así vivieron durante mucho tiempo, y un día Sibö le dice a Cacao: - Vamos a bañarnos-; 
ellos se fueron a bañar; en eso se arregló Cacao muy bonita; Sibö se vistió como los otros, recuperó la elegancia. Skwaröm, Wëröm, SLo', éstas les dijeron que volvieran a donde ellas, pero ya éstos se habían ido y no volvieron. Se fueron con su elegancia. (Bozzoli, 1977: 186)

Otra versión que muestra mejor la relación que establecen Sibö y Tsiru es:

...La primera era /skwaetmía/, la segunda era /wërtmía/, la tercera era /kchiLtmía/, y la cuarta era /chöLtmia/. Todas eran jóvenes. El pensó y se dijo: iQué mujeres más bellas!El las quería, pero ninguna lo quería a él. Entonces él se disfrazó de cuerpo sucio, lleno de llagas, de bubas, hediondo. Por eso /kchLtmí/, /skaLomtmi/, /wërutmí/, y /sLotmi/, todas ellas se decían: ¿Para qué nos sirve un hombre tan feo y hediondo como él? El les preguntó a ellas, - ¿cuál de ustedes me quiere? -. Ellas contestaban: -ninguna de nosotras-, tú eres feo, hediondo, - ¿para qué nos puedes servir? -. Ajá, ¿cómo será mejor hacerlo?, pensó él. Entonces se dirigió a la última, que era /tsiru'/, Cacao, Que entonces era en forma de mujer, y que se llamaba / tsirutmíacha/ tsruktmia/, y le preguntó si lo quería, porque a ella /sibö/ si la dejó ver su propia personalidad. (Bozzoli, 1979: 171).

De la historia anterior, y de otras versiones escuchadas en Talamanca, se puede inferir que Tsirú, ha sido favorecida por Sibö ("Dios", héroe cultural de los bribris), siendo elegida entre sus hermanas (otras especies de cacao que se encuentran en Talamanca) para ser la bebida espiritual de los bribris. Existe una equivalencia simbólica entre sangre y chocolate (la bebida de cacao) para los bribris (Bozzoli, 1979). Por tanto, el chocalate tsiru di, es una bebida que toma una importancia significativa en los ritos de iniciación y purificación. El chocolate por ejemplo, es utilizado para la purificación de impurezas relacionadas con los nacimientos y muertes (Bozzoli,1979) Por ejemplo, el cacao se utiliza como elemento purificador de la impureza del nya y el bukuru (impurezas relacionadas con nacimientos y muertes). En el caso de los enterradores (okompa), el cacao es usado fundamentalmente para lavar las manos del okom (singular de okompa) y sus ayudantes, con la finalidad de evitar la contaminación por la impureza de la muerte.

Otro cargo tradicional relacionado con los ritos fúnebres, es la Tsirú Okom, exclusivamente femenino y muy respetado en Talamanca, es la encargada de la elaboración del chocolate especial para el rito fúnebre, se mantiene, pero con riesgo de extinción.

Salazar (2012), muestra el rol clave que juegan los guías locales en desarrollo del turismo de base comunitaria. En efecto, son los guías locales indígenas, quienes ejercen un papel en la trasmisión del acervo cultural y por qué no, en la forma de revitalizar su patrimonio inmaterial. Estudios como el de Weiler y Ham $(2001,2002)$, señalan la importancia de los procesos de formación de los guías en interpretación del patrimonio, en el contexto de países latinoamericanos.

Un ejemplo de lo comentado anteriormente, es el papel que juegan los guías locales indígenas con relación a que se lleven a cabo mejoras en la experiencia turística en Talamanca. Hasta el año 2012, para los indígenas bribris solamente existía la posibilidad de formarse como guías generales o naturalistas. A partir de esta limitación, los grupos 
organizados de mujeres, con el apoyo de varios emprendimientos turísticos, solicitaron apoyo al ITCR para la creación de un programa de formación de guiado turístico indígena, centrado en su patrimonio cultural. Después de varios años de trabajo conjunto con la comunidad de Talamanca, se diseñó un programa de formación contextualizado a la realidad de Talamanca y avalado por el ICT, el primer proyecto de formación en guiado turístico cuyo enfoque principal, fue el patrimonio cultural indígena y a través del cual se otorgaba la licencia de Guía Local Indígena (Arias, 2019). Los egresados de este programa han sido, los guías base de la Asociación de Guías Indígenas Bribris de Talamanca (AGITUBRIT), quienes en el año 2017, constituyeron al mismo tiempo, la primera agencia receptiva de turismo indígena de Costa Rica: AGITUBRIT TOUR.

Los guías locales indígenas de AGITUBRIT representan a su vez, a los emprendimientos turísticos en sus comunidades (en total nueve), abriéndose de esta forma, oportunidades para establecer una Ruta Turística articulada que gire en torno a la producción del cacao. Esto podría servir, al mismo tiempo, como fortalecimiento de los conocimientos de los guías locales sobre la tradición oral que existe sobre los simbolismos del cacao. Para que esto fuera viable, los guías deberían consultar a las autoridades tradicionales, primero, sobre aquellos elementos del patrimonio cultural inmaterial que pudieran ser puestos en valor para el turismo, y segundo, sobre las posibilidades de su participación como guardianes de la cultura, ligados en todo momento a procesos de formación para actualizar los conocimientos, forma y métodos de interpretar el patrimonio. Por otro lado, deberían de tenerse en cuenta a aquellos emprendimientos turísticos interesados en el proyecto, con la finalidad de hacerles partícipes del proceso.

\section{Figura 3 \\ ESTUDIANTES DEL PLAN DE GUÍAS LOCALES INDÍGENAS EN RECORRIDO TURÍSTICO ORGANIZADO POR LA ESTUDIANTE KARLA CALVO COMO SU PROYECTO FINAL REQUISITO DE OBTENCIÓN DE SU LICENCIA DE GUIADO (NÓTESE AL LADO IZQUIERDO AL KEKEPA CON EL BASTÓN)}

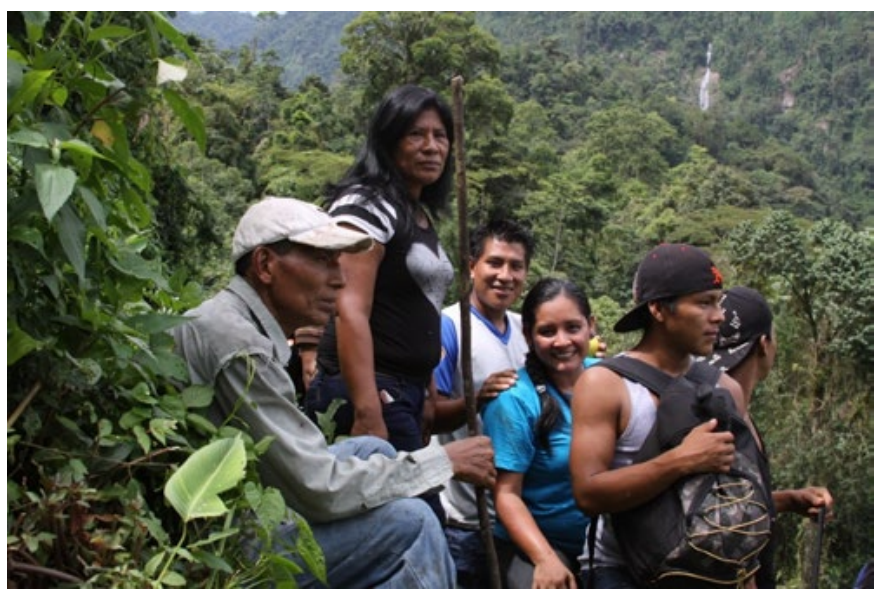




\section{CONCLUSIONES}

Fuente: Foto David Arias (2014).

El contexto de crisis sanitaria mundial por la COVID-19, unida a la crisis ambiental global y en particular, a la difícil situación económica que vive el sector turístico, sugiere repensar las formas convencionales de hacer turismo. Esto implica ser conscientes del alcance que puede tener el desarrollo de un determinado modelo turístico, en las comunidades receptoras. El turismo en el contexto de las comunidades indígenas, debe ser controlado de forma participativa e inclusiva por hombres y mujeres, siendo imprescindible, partir de una planificación conjunta en la toma de decisiones, sobre todo en relación al patrimonio que las comunidades están dispuestas a poner en valor turístico, con el fin de reducir los impactos negativos que implica la patrimonialización cultural. No debemos olvidar, que existen elementos culturales que no deben ser comercializados.

Los emprendimientos de turismo vinculados al cacao en Talamanca, muestran una participación activa de los grupos de mujeres indígenas. Los simbolismos presentes sobre esta tipología de cultivo evidencian, una estrecha relación con la femineidad, sin embargo, aún más interesante es, el rol de liderazgo que asumen las mujeres bribris, que rompe con una colonialidad de género de más de 500 años de imposición. Esto sugiere que el sistema histórico matrilineal bribri, debe ser entendido más allá de un patriarcado histórico. Del presente trabajo se desprende la ampliación de las posibilidades de existencia de sistemas matrilineales y patrilineales con relaciones de género aparentemente más equitativas entre hombres y mujeres, como sucede en el caso de las comunidades de Abya Yala, sin generalizar. No obstante, y dada su importancia, este debe ser un tema estudiado en mayor profundidad.

El proceso de puesta en valor del patrimonio cultural inmaterial, como el caso de los simbolismos de cacao, debe de llevar todo un proceso de consulta con las propias comunidades, con la finalidad de ser avalado y consensuado. En estos procesos, es fundamental, la participación activa de las autoridades tradicionales, guías locales y emprendimientos turísticos, así como la comunidad en general. Es importante que se lleven a cabo procesos participativos avalados por las comunidades indígenas, de los que se obtengan como resultado el empoderamiento como oportunidad de "desarrollo", en el sentido de las nociones de "buen vivir" de los pueblos indígenas de Abya Yala.

Se ha identificado que, en la mayoría de los emprendimientos de turismo indígena, la oferta actual de actividades, gira en torno al cacao. Sin embargo, tal y como se desprende de los estudios llevados a cabo en el presente trabajo, existe un gran potencial turístico, relacionado con los simbolismos. Hablamos de una parte importante del patrimonio cultural inmaterial, que, debido al fuerte proceso de aculturación, está en riesgo de desaparición. En este sentido, se hace aún más necesario, poner en marcha procesos participativos de recuperación de los saberes tradicionales del cultivo del cacao. Dar respuesta a las necesidades de mejora de producto turístico en base al cacao, en consonancia con su identidad y herencia cultural, puede ayudar a la mejora local de los emprendimientos turísticos, los productores de cacao y los guías locales; así como para la recuperación y protección del patrimonio cultural inmaterial asociado a su cultivo. 
A pesar de la tendencia a la baja en la producción cacaotera en los últimos años en Costa Rica, el cacao sigue siendo uno de los cultivos comerciales más importantes (después del plátano y del banano) para la agricultura en las comunidades indígenas de Talamanca. No obstante, el poco valor agregado que existe, en la producción, es un factor limitante para mejorar los ingresos económicos de las familias. En la actualidad existen pocas capacidades instaladas de infraestructuras y tecnologías para dar valor agregado a la producción comunitaria, por tanto, los mayores beneficios de la producción de cacao orgánico de buena calidad no necesariamente quedan en las y los productores indígenas.

Debido a las potencialidades que detenta el cacao y sus simbolismos como patrimonio cultural inmaterial, además de tratarse de un producto de calidad, producido de muchas veces con impacto ambiental mínimo, sería pertinente explorar las oportunidades propuestas en el presente trabajo, con la finalidad de dar respuesta a las necesidades de mejora de producto turístico de la comunidad indígena bribri, poniendo en valor unas señas de identidad únicas derivadas de la producción del cacao, a la vez que diversificando la oferta turística y complementando ingresos en la comunidad.

\section{REFERENCIAS}

ACUÑA, V. (2002): « La invención de la diferencia costarricense, 1810-1870», Revista de Historia, San José, Costa Rica, n 45, pp. 191-228.

ADIE, B. A. y HALL, C.M. (2017): «Who visits World Heritage? A comparative analysis of three cultural sites», Journal of Heritage Tourism, vol. 12 (1), pp. 67-80.

AGUILAR, E. (2003): «La Cultura como recurso en el ámbito de la globalización: la nueva dinámica de las industrias artesanas», en Las Expresiones Locales de la Globalización: México y España. México, Porrúa-Ciesas-Universidad Iberoamericana, pp. 405-423.

AICKEN, M. y RYAN, C. (Eds) (2005): Indigenous Tourism. London, Routledge.

ALVIM, P.D.T. (1977): “Cacao", en Ecophysiology of tropical crops, pp. 279-313

ARIAS HIDALGO, D. (2019): «Extensión universitaria y turismo: una reflexión sobre el proceso de formación de guías de turismo en Talamanca, Costa Rica», Trama. Revista de Ciencias Sociales y Humanidades, vol. 8 (2), pp. 94-114.

ARIAS HIDALGO, D. y SOLANO BRENES, J. (2009): Programa de capacitación para guías turísticos locales en territorio indígena de Talamanca. Proyecto de Graduación para la obtención de Bachillerato en Gestión de Turismo Sostenible. ITCR, Costa Rica.

ARIAS-HIDALGO, D. (2016): «Caracterización de albergues turísticos y percepciones sobre el turismo en el Territorio Indígena Bribri talamanqueño», Trama. Revista de Ciencias Sociales y Humanidades, vol. 5 (1), pp. 22-32.

ARIAS-HIDALGO, D. y MÉNDEZ-ESTRADA, V. (2015): «Diferencias en la vivienda, albergues turísticos, lenguaje, el parentesco y percepción del turismo en las comunidades Bribri con diferentes niveles de aislamiento geográfico (Talamanca, Costa Rica)», Cuadernos de Investigación UNED, vol. 7 (2). pp. 119-129.

ARIAS-HIDALGO, D., AGUILAR-ÁLVAREZ, R. y REINHOLD, D. (2019): «Prácticas sostenibles de turismo para el tratamiento de aguas y manejo de residuos sólidos en 
albergues turísticos de Talamanca», Revista Tecnología en Marcha, vol. 32 (6), pp. 78-88.

ASENSIO, R. y PÉREZ, B. (2012): ¿ El turismo es cosa de pobres? Patrimonio cultural, pueblos indígenas y nuevas formas de turismo en América Latina. Universidad de La Laguna, Colección PASOS edita, $\mathrm{n}^{\circ} 8$.

BACHOFEN, J (1992): El matriarcado: una investigación sobre la ginecocracia en el mundo antiguo según su naturaleza religiosa y jurídica. Madrid, Akal, segunda edición.

BANCO MUNDIAL (2015): Latinoamérica indígena en el siglo XXI: Primera década. Washington, Banco Internacional de Reconstrucción y Fomento/Banco Mundial.

BENNETT, N., LEMELIN, R. H., KOSTER, R. y BUDKE, I. (2012): «A capital assets framework for appraising and building capacity for tourism development in aboriginal protected area gateway communities», Tourism Management, vol. 33 (4), pp. 752-766. BOUDE, O. y LUNA, M. (2013): «Gestión del conocimiento: salvaguardia del Patrimonio Cultural Inmaterial del Carnaval de Barranquilla», Opción, vol. 29 (71), pp. 27-44.

BOURGOIS, P. (1994): Banano, etnia y lucha social en Centro América. San José, Editorial Departamento Ecuménico de Investigaciones.

BOZZOLI DE WILLE, M.E. (1977): «Narraciones bribris», Vínculos, vol. 2 (2), pp. 165-199.

BOZZOLI DE WILLE, M.E. (1979): El nacimiento y la muerte entre los bribris. San José, Editorial Universidad de Costa Rica.

BOZZOLI DE WILLE, M.E. (1967): Sobre el sistema de parentesco de los bribris. Trabajo de incorporación a la Academia de Historia y Geografía, San José.

BOZZOLI DE WILLIE, M.E. (1980): "Continuidad del simbolismo del cacao, del siglo XVI al siglo XX", en Memoria del Congreso sobre el mundo centroamericano de su tiempo (V centenario de Gonzalo Fernández de Oviedo). San José, Costa Rica, Editorial Texto, pp. 229-240.

CABNAL, L. (2010): «Acercamiento a la construcción de la propuesta de pensamiento epistémico de las mujeres indígenas feministas comunitarias de Abya Yala», en Momento de paro Tiempo de rebelión: Miradas feministas para reinventar la lucha. Minervas Ediciones, pp 116-134.

CÁCERES, R. (2000): Negros, mulatos, esclavos y libertos en la Costa Rica del siglo XVII. México, Instituto Panamericano de Geografía e Historia.

CAÑADA, E. (2015): «La comercialización del turismo comunitario en América Latina», en Anuario de Estudios Centroamericanos, Universidad de Costa Rica, n ${ }^{\circ}$ 41, pp. 59-189.

CAÑADA, E. (2019): Transformaciones en las relaciones de género en experiencias de turismo comunitario en Centroamérica. Barcelona, Alba Sud Editorial.

CARMIOL, G. (2017): Análisis de la actividad cacaotera costarricense y perspectivas de su reactivación. Costa Rica. San José, Sepsa.

CARRERA, G. y DIETZ, G. (2005): «Patrimonio inmaterial y gestión de la diversidad", Colección Cuadernos IAPH, $\mathrm{n}^{\circ}$ 17, pp.15-29.

CAVACO, C. (2011): «Turismo Rural Comunitário (trc) e desenvolvimento local na América Latina. Umolhareuropeu», en De Souza, M. y Elesbão, I. (Orgs.): Turismo 
Rural. Iniciativas e Inovações. Porto Alegre, Universidade Federal de Rio Grande do Sul, pp. 145-213.

CHACÓN, A. (2014): "Informe final estado de la agricultura", en Vigesimoprimer Informe Estado de la Nación en Desarrollo Humano Sostenible 2014.

CHANG, G. (2017): «Diagnóstico del patrimonio cultural intangible de Costa Rica: instrumento para reconocer la diversidad cultural», Inter Sedes, $\mathrm{n}^{\circ}$ 37, pp.1-14.

CHAVES. (2012): “O turismo étnico em comunidades indígenas no Brasil: a Reserva Pataxó da Jaqueira e o Parque Indígena do Xingu”. PASOS. Revista de Turismo y Patrimonio Cultural, vol. 8, pp. 115-129.

CHAVES, R., SALAZAR. y ROBLES, C. (2016): Industrialización y Comercialización de Cacao Orgánico en Talamanca: un Enfoque de Agronegocios. Informe Técnico. ITCR. Disponible en::https://repositoriotec.tec.ac.cr/handle/2238/6836

CORONADO, G. (2014): «Selling Culture? Between Commoditisation and Cultural Control in Indigenous Alternative Tourism», PASOS. Revista de Turismo y Patrimonio Cultural, vol. 12 (1), pp. 11-28.

CUMES, A. (2017): «La cosmovision maya et le patriarcat: une interprétation critique», Recherches Féministes, vol. 30 (1), pp. 47-59.

DELGADO, A. (2008): «Barro, madera, cuero y oro: breve acercamiento al mundo de las artesanías en la ciudad de Écija», en Martín Pradas, A. (Coord.) Actas de las VI Jornadas de Protección del Patrimonio Histórico de Écija. Patrimonio inmaterial de Écija II,costumbres, artesanía y tradiciones culinarias. Écija, Asociación de Amigos de Écija, pp. 55-76.

ENDERE, M. (2009): «Algunas reflexiones acerca del patrimonio», en Endere, M. y J. Prado (Eds.): Patrimonio, Ciencia y Comunidad. Su abordaje en los partidos de Azul, Olavarría y Tandil. Olavarría, Universidad Nacional del Centro de la Provincia de Buenos Aires, pp.19-46.

FLORES, G. y NAVA, F. (2016): Identidades en venta. Músicas tradicionales y turismo en México. México, Instituto de Investigaciones sociales Universidad Nacional Autónoma de México.

FONSECA, E. (1983). Costa Rica colonial: la tierra y el hombre. San José, EDUCA.

FULLER, D., BUULTJENS, J. y CUMMINGS, E. (2005): «Ecotourism and indigenous micro-enterprise formation in northern australia opportunities and constraints», Tourism Management, vol. 26 (6), pp. 891-904.

FUlleR, D., CALDICOTT, J., CAIRNCROSS, G. y WILDE, S.J. (2007): «Poverty, Indigenous culture and ecotourism in remote Australia», Development, vol. 50 (2), pp. 141-148.

GARCÍA, N. (2000): La globalización imaginada. Barcelona, Paidós.

GIACOMASSO, M.V. (2017): «Patrimonio cultural indígena: representaciones y prácticas rankülches en "Pueblo Ranquel” (Argentina)», Revista Austral de Ciencias Sociales, $\mathrm{n}^{\circ} 33$, pp. 103-121.

GRÜNEWALD, R. (2003): «Turismo e etnicidade», Horizontes Antorpológicos, $\mathrm{n}^{\circ}$ 20, pp. 141-159. 
GUEVARA, M. (Coord.) (2000): Perfil de los pueblos indígenas de Costa Rica. Informe final. RUTA/ Banco Mundial.

HALE, C. (2002): «Does multiculturalism Menace? Governance, Cultural rights and the politics of identity in Guatemala», Journal of Latin American Studies, vol. 34 (3), pp. $485-524$.

HEINICH, N. (2009): La Fabrique du patrimoine. De la cathédrale à la petite cuillère. Paris, Éditions de la Maison des Sciences de l'Lomme/Ministère de la Culture et de la Communication, coll. Ethnologie de la France.

HERNANDO, A. (2009): «El patrimonio: entre la memoria y la identidad de la modernidad», Revista $p h, \mathrm{n}^{\circ} 70$, pp. 88-97.

HIDALGO-CAPITÁN, A.L. (2003): Costa Rica en evolución: política económica, desarrollo y cambio estructural del sistema socioeconómico costarricense (1980-2002). San José, Editorial de la Universidad de Costa Rica.

IBARRA, E. (2010): Etnohistoria de las actividades socioeconómicas y políticas de los indígenas del borde caribeño de Centroamérica en los siglos XVI y XVII. Informe final. UCR.

INEC (Instituto Nacional de Estadísticas y Censos) (2011): Territorios indígenas: principales indicadores demográficos y socioeconómicos, censo 2011. INEC Costa Rica. Disponible en:: https://www.inec.go.cr/documento/censo-2011-territorios-indigenasprincipales-indicadores-demograficos-y-socioeconomicos

JIMÉNEZ, C. (2020): «Construir en piedra seca. Salvaguardar el patrimonio cultural inmaterial», Gazeta de Antropología, vol. 36 (1).

JOHNSTON, A. (2006): Is the sacred for sale: Tourism and Indigenous peoples. London, Routledge.

JOUAULT, S. (2018): Mayas d'hier et d'aujourd'hui: le rôles des sociétés locales dans le développement touristique. Rennes, Pressesuniversitaires de Rennes.

KIEFFER, M. (2018): «Turismo Rural Comunitario y organización colectiva: un enfoque comparativo en México », PASOS. Revista de Turismo y Patrimonio Cultural, vol. 16 (2), pp. 429-441.

KRISCHE, P. (1930): El enigma del matriarcado. Madrid, Revista de Occidente.

LÉVI-STRAUSS, C. (1969): The elementary structures of kinship: London, Eyre \& Spottiswoode.

LÓPEZ, A. y MARÍN, G. (2010): «Turismo, capitalismo y producción de lo exótico: una perspectiva crítica para el estudio de la mercantilización del espacio y la cultura», Relaciones. Estudios de Historia y Sociedad, vol.31 (123), pp. 219-260.

LOWES, S. (2020): Matrilineal kinship and spousal cooperation: Evidence from the matrilineal belt. Stanford, University and CIFAR. Disponible en:https://scholar.harvard.edu/files/slowes/files/lowes_matrilineal.pdf

LUGONES, M (2008): «Colonialidad y Género». Tabula Rasa, n 9, pp. 73-102.

MACLEOD, P. (1996): «Auge y estancamiento de la producción de cacao en Costa Rica 1660-95", en Anuario de Estudios Centroamericanos, pp. 83-107. 
MALDONADO, C. (2006): Turismo y comunidades indígenas: impactos, pautas para autoevaluación y códigos de conducta. Organización Internacional del Trabajo, Serie Red de Turismo Sostenible Comunitario para América Latina (REDTURS). Disponible en:https://www.ilo.org/wcmsp5/groups/public/---ed_emp/---emp_ent/---ifp_seed/ documents/publication/wcms_117521.pdf

MARCOS, J. (2010): «El patrimonio como representación colectiva. La intangibilidad de los bienes culturales», Gazeta de Antropología, artículo 19. Disponible en::http://www. ugr.es/ pwlac/G26_19Javier_Marcos_Arevalo.html

MARTÍN-CANO, F. (2005): «Estudio de las sociedades matrilineales (S. M.)», Nomadas. Revista Crítica de Ciencias Sociales y Jurídica, vol. 12 (2), pp. 197-205.

MARTÍNEZ MAURI, M. (2014): «Relaciones de género, vestimenta y artesanías indígenas: el caso de la mola de los kunas en Panamá», en Celigueta, G., Orobitg, G. y Pitarch, P. (Coords.) Modernidad indígena, 'indigeneidad'e innovación social desde la perspectiva del género. Barcelona, Universitat de Barcelona.

MATTISON, S. (2016): "Matrilineal and Matrilocal Systems", en The Wiley Blackwell Encyclopedia of Gender and Sexuality Studies, pp. 1-6.

MENCHEN, D. (2012): Brasil tem 305 etnias e 274 línguas indígenas, aponta Censo 2010, en Folha de São Paulo. Disponible en:: http://www1 folha.uol.com.br/poder/1135045brasil-tem-305-etnias-e-274-linguas-indigenas-aponta-censo-2010.shtml

MIDEPLAN. (Ministerio de Planificación Nacional y Política Económica) (2013): Índice de desarrollo social 2013. San José, Costa Rica. Disponible en:: www.mideplan.go.cr

MILANO, C. (2016): «Antropología, turismo y desarrollo en cuestión: el turismo comunitario a debate», Quaderns de l'Institut Català d'Antropologia, no 32, pp. 123-143.

MORALES, J. (1987): “Cuna”, en Introducción a la Colombia Amerindia, Bogotá, Instituto Colombiano de Antropología, pp. 263-277.

MOTAMAYOR, J.C., RISTERUCCI, A.M., LOPEZ, P.A., ORTIZ, C.F., MORENO, A. y LANAUD, C. (2002): «Cacao domestication I: the origin of the cacao cultivated by the Mayas», Heredity, vol. 89 (5), pp. 380-386.

MUNJERI, D. (2009): «Following the length and breadth of the roots some dimensions of intangible heritage», en Smith, N. y Akagawa, L. (Eds.) Intangible Heritage. London, Routledge Taylor, pp. 131-150.

NACIONES UNIDAS (2007): Declaración de Naciones Unidas sobre los Derechos de los Pueblos Indígenas. Disponible en::https://www.un.org/esa/socdev/unpfii/documents/ DRIPS_es.pdf

NACIONES UNIDAS (2015): Objetivos de desarrollo sostenible (ODS) 2030. Disponible en:: https:/www.un.org/sustainabledevelopment/es/2015/09/la-asamblea-generaladopta-la-agenda-2030-para-el-desarrollo-sostenible/

NACIONES UNIDAS (2015): Asamblea General de Naciones Unidas. Disponible en:: https://www.un.org/es/ga/70/presskit/background.shtml

NAVARRETE, R. (2010): «Gobernabilidad neoliberal y movimientos indígenas en América Latina», Polis. Revista Latinoamericana, $\mathrm{n}^{\circ} 27$, pp. 1-16.

OEHMICHEN BAZAN, C. y DE LA MAZA CABRERA, F. (2019): «Turismo, pueblos indígenas y patrimonio cultural en México y Chile», PASOS. Revista de Turismo y Patrimonio Cultural, vol. 17 (1), pp. 53-64. 
OLIVERA, A. (2011): «Patrimonio inmaterial, recurso turístico y espíritu de los territorios». Cuadernos de Turismo, n 27, pp. 663-677.

PAREDES, J. (2013): Hilando fino. Desde el feminismo comunitario. México, Cooperativa El Rebozo.

PASTOR, M.J. y ESPESO-MOLINERO, P. (2015): «Capacitación turística en comunidades indígenas. Un caso de Investigación Acción Participativa (IAP)», El Periplo Sustentable, no 29 , pp. 171-208.

PEREIRO, X. (2015): «Reflexión antropológica sobre el turismo indígena», Desacatos, $n^{\circ} 47$, pp. 18-35.

PÉREZ, B. (2008): «El Patrimonio inmaterial en proyectos de desarrollo territorial en comunidades indígenas de Los Andes peruanos», Revista Electrónica de Patrimonio Histórico, no 3 , pp. 1-26.

POWIS, T., HURST, W.J., RODRIGUEZ, M., ORTIZ. P., BLAKE. M. ET AL. (2008): «The origins of cacao use in Mesoamerica». Mexicon, vol. 30 (2), pp. 35-38

PRATS, L. (2007): Antropología y Patrimonio. Barcelona, Editorial Ariel.

QUIJANO, A. (2000): «Colonialidad del poder: Eurocentrismo y América Latina», en La Colonialidad del saber: Eurocentrismo y ciencias sociales. Perspectivas Latinoamericana. Buenos Aires, CLACSO. pp. 201-246.

QUINTERO, V. (2005): «El patrimonio intangible como instrumento para la diversidad cultural ¿una alternativa posible?», en Carrera , G. y Dietz, G. (Coords.) Patrimonio inmaterial y gestión de la diversidad. Sevilla, Consejería de Cultura de la Junta de Andalucía-Instituto Andaluz del Patrimonio Histórico, pp. 68-83.

RIVERA CUNCICANQUI, S. (2010): Ch'ixinakaxutxiwa. Una reflexión sobre las prácticas y discursos descolonizadores. Buenos Aires, Tinta Limón.

RUÍZ FERNÁNDEZ, A.R, ARIAS HIDALGO, D. y SOLANO BRENES, J. (2019): «Bribri Kinship Relations: The Social Implications of a Matrilineal System», en Costa Rican Traditional Knowledge According to Local Experiences. Springer, Cham, pp. 127-141.

SALAZAR, N. (2012): «Community-based cultural tourism: issues, threats and opportunities», Journal of Sustainable Tourism, vol. 20 (1), pp. 9-22.

SEGATO, R. (2003): Las estructuras elementales de la violencia. Buenos Aires, Prometeo.

SOLÓRZANO, J.C. (2017): «La población indígena de Costa Rica en el siglo XVI al momento del contacto con los europeos», Anuario de Estudios Centroamericanos, $\mathrm{n}^{\circ}$ 43, pp. 313-345.

UNESCO (2003): Convención para la Salvaguardia del Patrimonio Cultural Inmaterial. París. Disponible en:: http://portal.unesco.org/es/ev.php-URL_ID=17716\&URL_ DO=DO_TOPIC\&URL_SECTION=201.html

UNESCO (2005): Convención sobre la Protección y Promoción de la Diversidad de las Expresiones Culturales. París. Disponible en:: http://www.unesco.org/new/es/culture/ themes/cultural-diversity/cultural-expressions/the-convention/convention-text

VALCUENDE DEL RÍO, J.M. (2017): «Experiencias turísticas indígenas en la región de Madre de Dios (Perú)», Gazeta de Antropología, vol. 33 (1). 
VARGAS, M. (2016): «Labranza académica: Impacto positivo de la División de Educación Rural en el desarrollo de las comunidades rurales e indígenas», Revista Electrónica Educare, vol. 20 (1), pp.1-15.

WEILER, B. y HAM, S. (2001): «Tour guides and interpretation», en The Encyclopedia of ecotourism. Wallingford, CABI. pp. 549-563

WEILER, B. y HAM, S. (2002): «Tour guide training: A model for sustainable capacity building indeveloping countries », Journal of Sustainable Tourism, vol. 10 (1), pp. 52-69

WHITFORD, M. y RUHANEN, L. (2014): «Indigenous tourism businesses: An exploratory study of business owners' perceptions of drivers and inhibitors», Tourism Recreation Research, vol. 39 (2), pp. 149-168.

YANG, L. y WALL, G. (2009): «Ethnic tourism: a framework and an application», Tourism Management, vol. 30 (4), pp. 559-570. 